\title{
RECOMENDAÇÕES DO BANCO MUNDIAL (BM) PARA AS POLÍTICAS PÚBLICAS EDUCACIONAIS BRASILEIRAS ${ }^{1}$
}

Egeslaine de Nez

Berenice Lurdes Borssoi

RESUMO: Historicamente, as reformas da Educação Superior na América Latina sofrem influências do Banco Mundial, que seguem o pensamento hegemônico, além do diagnóstico realizado pelos organismos internacionais. A educação é considerada por essas agências como mola propulsora do desenvolvimento econômico e combate da desigualdade. Contudo, apostar somente na educação não resolverá o problema social. O presente texto tem como objetivo compreender as atuais propositivas do Banco Mundial que estão presentes na construção de políticas públicas educacionais em países em desenvolvimento como o Brasil. Com base na abordagem qualitativa, este texto foi construído por meio da pesquisa bibliográfica e documental. As análises preliminares dos documentos sinalizam que o BM é chamado para assumir um papel nítido no sentido de organizar a economia. Sua ação vai se configurando politizada, abrangente e intrusiva. Há muito que se pesquisar e analisar sobre suas práticas e a incidência na reestruturação das políticas sociais brasileiras.

PALAVRAS-CHAVE: Políticas Públicas. Organismos Internacionais. Estado.

\section{INTRODUÇÃo}

Historicamente, as reformas da Educação Superior na América Latina sofrem influências do Banco Mundial, que seguem o pensamento hegemônico, além do diagnóstico realizado pelos organismos internacionais. Entre eles, destacam-se o Fundo Monetário Internacional (FMI), a Organização Mundial do Comércio (OMC) e a Organização das Nações Unidas para a Educação, a Ciência e a Cultura (UNESCO) entre demais instituições presentes no mundo inteiro.

O último relatório do Banco Mundial (2017) aponta três eixos centrais: erradicar a pobreza extrema, impulsionar a prosperidade compartilhada, além de promover a resiliência. Para isso, aposta na educação, considerada como propulsora desses elementos com vista ao desenvolvimento e combate da desigualdade. Contudo, responsabilizar apenas um campo social, no caso a educação, no combate à desigualdade, é acrítico, sobretudo, num contexto político de ajustes fiscais.

Levando em consideração essa contraposição, o texto propõe uma reflexão e ampliação do campo analítico no que tange ao questionamento do papel não aparente do Banco Mundial (BM) no fortalecimento e expansão do capital diante suas crises e a definição de políticas públicas a serem 'oficializadas'. Associado a isso, vale-se de uma proposta nova a manutenção dos países na condição de dependência financeira diante um contexto de ajuste fiscal e a objetivação da lógica de mercado (menor custo/mais produtividade) nas políticas públicas educacionais, presentes na formação (básica e superior).

Este texto objetiva compreender as atuais propositivas do BM que estão presentes na construção de políticas públicas educacionais, para os países em desenvolvimento como o Brasil. Assim, utilizou-se de pesquisa bibliográfica e levantamento documental a partir dos referencias teóricos oficiais dos órgãos analisados.

O artigo está dividido em cinco partes, a primeira traz as considerações preliminares sobre a pesquisa realizada, enfatizando o objetivo; num segundo momento, apresenta-se o referencial que aponta elementos teóricos sobre as políticas do BM que impactam nas públicas educacionais

1 Uma primeira versão deste estudo foi apresentada no IV Seminário Internacional do HISTEDBR - Desafios do Trabalho e Educação no século XXI, na Universidade Federal de Uberlândia (UFU), em 2019. 
brasileiras; posteriormente, sinalizam-se os procedimentos metodológicos utilizados na investigação; a quinta parte sinaliza os resultados analíticos com base em dois relatórios do BM (2017 e 2018); e, por fim, as considerações.

\section{Perspectivas teóricas: Papel social, técnico e político do BM}

Que educar é - citando Gramsci - colocar fim à separação entre Homo Faber e Homo Sapiens; é resgatar o sentido estruturante da educação e de sua relação com o trabalho, as suas possibilidades criativas e emancipatórias. E recorda que transformar essas ideias e princípios em práticas concretas é uma tarefa a exigir ações que vão além dos espaços das salas de aula, dos gabinetes e dos fóruns acadêmicos. Que a educação não pode ser encerrada no terreno estrito da pedagogia, mas tem de sair às ruas, para os espaços públicos, e se abrir para o mundo (MÉSZÁROS, 2008, p. 10-11).

O Banco Mundial integra o chamado Grupo Banco Mundial (GBM)2, sendo uma das maiores fontes de financiamento do mundo para os países em desenvolvimento, composto por cinco instituições ${ }^{3}$, que objetivam reduzir a pobreza, aumentar a prosperidade compartilhada e promover o desenvolvimento sustentável. Todas as atividades que se caracterizam como ligadas ao 'desenvolvimento' são objetos da ação do Banco, o que o distingue radicalmente do FMI e de outras agências especializadas das Nações Unidas (PEREIRA, 2018). Importa saber, todavia que:

Os contratos de empréstimo do Banco Mundial trazem condicionalidades (exigências) sobre o que os governos dos Estados clientes devem ou não fazer em matéria de política econômica e políticas públicas em geral. [...] todo Estado cliente tem de ser membro do Banco, mas nem todo membro é cliente. Significa dizer que o Banco Mundial nada prescreve aos países mais ricos e com maior gravitação dentro da instituição (como EUA, Reino Unido, Alemanha, Japão, França e Canadá); ao contrário, deles recebe inúmeras pressões, a começar dos EUA (PEREIRA, 2018, p. 2189).

O EUA é o maior acionista e mais influente da instituição, exerce, portanto, um papel crucial na configuração das políticas e práticas do Banco, se beneficiando em termos econômicos e políticos. Mas, também possui seus interesses coorporativos e busca amenizar as pressões diante outros países. Desse modo:

Construindo a autoimagem de instituição politicamente neutra, o Banco sempre explorou a sinergia entre financiamento, assistência técnica a governos, pesquisa econômica e coordenação de iniciativas multilaterais (em saúde, educação, meio ambiente, etc.), com o objetivo de alavancar a sua influência e institucionalizar agendas políticas globais a serem assumidas pelos Estados clientes (PEREIRA, 2018, p. 2189).

Isto significa dizer que, embora seu interesse seja nas atividades técnicas não deixa de atuar no plano político, econômico, logo se caracteriza como "um ator político, intelectual e financeiro". Portanto, "a relação do Banco com os Estados envolve e implica também os grupos e as classes sociais, pois é da disputa e dos acordos de poder entre eles que se dá a política estatal". E

2 É constituído por sete organizações: 1) Banco Internacional para a Reconstrução e o Desenvolvimento (BIRD), criado em 1944; 2) Associação Internacional de Desenvolvimento (AID), criada em 1960; 3) Corporação Financeira Internacional (CFI), de 1956; 4) Centro Internacional para Conciliação de Divergências em Investimentos, de 1966; 5) Agência Multilateral de Garantias de Investimentos, de 1988; 6) Instituto de Desenvolvimento Econômico, de 1955, renomeado como Instituto do Banco Mundial em 2000; 7) Painel de Inspeção, fundado em 1993 (PEREIRA, 2018).

3 Banco Internacional de Reconstrução e Desenvolvimento (BIRD); Associação Internacional de Desenvolvimento (AID); Corporação Financeira Internacional (IFC); Agência Multilateral de Garantia de Investimentos (MIGA) e Centro Internacional para Arbitragem de Disputas sobre Investimentos (ICSID) (BANCO MUNDIAL, 2017). 
ainda, "a relação do Banco com os Estados não se limita ao governo e às agências estatais, mas envolve também organizações da sociedade civil e corporações privadas". Cabe esclarecer que: "os Estados dispõem de condições muito assimétricas de negociação, dependendo do tamanho de suas economias e do seu grau de dependência externa" o que infere nas negociações. (PEREIRA, 2018, p. 2189-2190).

Nesta direção, "é um ator social em meio a uma extensa rede de relações de agentes públicos, privados, não governamentais, filantrópicos, empresariais e financeiros que disputam os rumos, os meios e os significados do desenvolvimento, em escala nacional e global" (PEREIRA, 2018, p. 2190).

Então, não é novidade que os governos de Estado utilizarão as recomendações ou condicionalidades do Banco para materializar as reformas, contudo, pode oscilar entre as demandas da esfera federal, estadual e municipal de acordo com as orientações e prioridades dos governos, como também se modifica diante as lutas de classes. Ainda de acordo com Pereira (2018, p. 2190) "a eficácia das ações [...] necessita da combinação de coerção com persuasão, por meio da qual se constroem, por fora e por dentro dos espaços nacionais, visões de mundo e interesses mútuos, tanto na sociedade civil como nos aparelhos de Estado”. O Banco Mundial prevê algumas prioridades que orientam seu trabalho, verificar Figura 1:

Figura 1 - Prioridades das ações do Banco Mundial

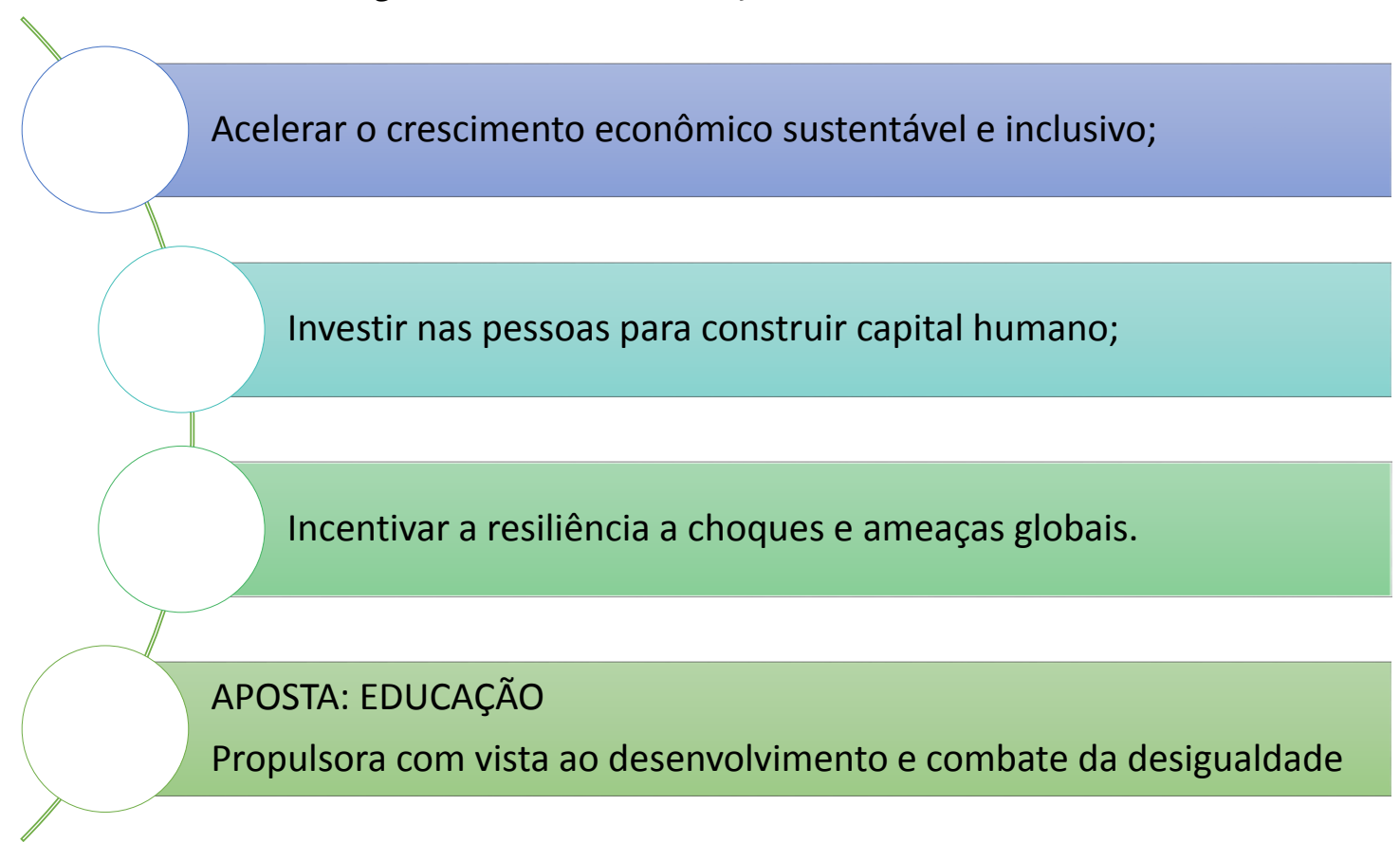

Fonte: Adaptado de Banco Mundial (2019).

Importa, neste estudo, especificamente discutir a segunda prioridade, pois se a história for retomada ver-se-á que as reformas na Educação Básica e Superior na América Latina e Caribe sofreram e, sofrem influências do Banco Mundial, que seguem o pensamento hegemônico e o diagnóstico realizado pelos organismos internacionais.

Entre os organismos internacionais destacam-se o FMI, a OMC e a UNESCO e demais instituições, que trabalham interligadas com o BM o qual busca instrumentalizar a política eco- 
nômica de forma a favorecer o 'mercado', deixando nas mãos da sociedade civil a alocação de recursos sem mediação estatal. Para Chesnais (2000),

O termo "mercado" é a palavra que serve hoje para designar pudicamente a propriedade privada dos meios de produção; a posse de ativos patrimoniais que comandam a apropriação sobre uma grande escala de riquezas criadas por outrem; uma economia explicitamente orientada para os objetivos únicos de rentabilidade e de competitividade e nas quais somente as demandas monetárias solventes são reconhecidas. As fusões-aquisições dos últimos anos empurraram o processo de concentração a níveis que pareciam impossíveis até vinte anos atrás. Atrás do eufemismo do "mercado", encontram-se formas cada vez mais concentradas de capital industrial e financeiro que detêm um poder econômico sempre maior, que inclui uma capacidade muito forte de "colocar em xeque o mercado", "curto-circuitar" e cercar os mecanismos da troca "normal" (p. 7 - grifos do autor).

Essa política econômica se instituiu fortemente com a globalização e a mundialização do capital por meio do neoliberalismo. Segundo Dardot e Laval (2016), o neoliberalismo não é somente uma doutrina econômica ou ideologia, é uma nova racionalidade de mundo, que estrutura e organiza tanto as ações dos governantes como a própria conduta dos governados. Não é simplesmente a continuidade do liberalismo clássico do século XVIII, nem a sua negação, mas um "sistema normativo que ampliou sua influência ao mundo inteiro, estendendo a lógica do capital a todas as relações sociais e a todas as esferas da vida" (p. 7).

Em sendo desta forma, é a nova racionalidade do capitalismo no atual estágio deste século, que se fundamenta na concorrência em todos os âmbitos, inclusive na esfera do Estado. Essa nova racionalidade, "uma verdadeira razão-mundo" se realiza por etapas com finalidade de "extensão da racionalidade mercantil a todas as esferas da existência humana" (DARDOT e LAVAL, 2016, p. 379), isto é,

Da construção do mercado à concorrência como norma dessa construção, da concorrência como norma da atividade dos agentes econômicos à concorrência como norma da construção do Estado e de sua ação e, por fim, da concorrência como norma do Estado-empresa à concorrência como norma da conduta do sujeito-empresa [...] (p. 379).

Essa racionalidade propõe o desaparecimento e/ou separação entre esfera privada e esfera pública, corroendo os fundamentos da própria democracia liberal, e, dentre outros efeitos, dilui o direito público em benefício do privado, propondo a conformação da ação pública aos critérios de rentabilidade e da produtividade e a promoção do 'cidadão-consumidor' (DARDOT e LAVAL, 2016).

Na década de 90, no Brasil, a mudança na concepção e ação do Estado vem amalgamada com a Reforma num contexto de economia competitiva, com padrão de acumulação flexível (HARVEY, 1992) com transformações no mundo do trabalho e no campo educacional.

[...] foi conduzida pelo Ministério da Administração e Reforma do Estado (MARE), na gestão do então presidente Fernando Henrique Cardoso (1995-2003), e objetivava a construção de um modelo de Estado Social-Liberal. O Estado deveria ser reduzido, principalmente, quanto ao número de funcionários públicos, em razão dos programas de privatização, terceirização e "publicização"; e deveria ser fortalecido por meio de uma administração pública gerencial (new management public), que garantisse a governança e a governabilidade com a colaboração de instituições de intermediação de interesses. Ao delimitar a área de atuação do Estado, as universidades e centros de pesquisa cien- 
tificas e tecnológicas poderiam ser consideradas "serviços não exclusivos" do Estado, poderiam ser transferidos para instituições não estatais com ou sem subsídios públicos. As universidades, na concepção da reforma, desenvolvem atividades consideradas competitivas, que podem ser controladas pela administração pública gerencial (new management public) ou pela constituição das organizações nomeadas "quase mercados" (SOUZA, 2018, p. 88 - grifos do autor).

Naquele período e, sobretudo, no atual momento histórico, o Estado vem sendo reconfigurado em dois âmbitos: de fora, com privatizações maciças de empresas públicas que põe fim ao 'Estado produtor', consecutivamente, de dentro, com a instauração avaliação e regulação constantes que mobiliza novos instrumentos de poder e, estrutura relações diferenciadas e diversificadas entre governo e sujeitos (DARDOT e LAVAL, 2016).

Nesse estágio do capitalismo o Estado e, suas instituições pertencentes (como as escolas e universidades), passam a ser orientados pela lógica empresarial de concorrência. Isto tudo leva a perda da própria legitimidade e do significado essencial dos serviços públicos, que se tornam privados.

Assim, a investida do BM na promoção do capital humano como concepção educativa, propõe a libertação do ser humano para a reprodução de sua própria existência no mercado. A teoria do capital humano ${ }^{4}$ surge nos Estados Unidos em 1950 com a criação da disciplina de econômica de educação no departamento de Economia da Universidade de Chicago, tendo como fundador o professor Theodore W. Schult. Essa disciplina discutia ganhos de produtividade gerados pelo "fator humano". Tal concepção de trabalho humano, ao ser qualificado por meio da educação, era um dos meios de ampliar a produtividade econômica, isto é, de gerar lucros para o capital (MINTO, 2020).

Aplicada ao campo educacional, a ideia de capital humano gerou toda uma concepção
tecnicista sobre o ensino e sobre a organização da educação, o que acabou por mistificar
seus reais objetivos. Sob a predominância desta visão tecnicista, passou-se a disseminar
a ideia de que a educação é o pressuposto do desenvolvimento econômico, bem como do
desenvolvimento do indivíduo, que, ao educar-se, estaria "valorizando" a si próprio, na
mesma lógica em que se valoriza o capital. O capital humano, portanto, deslocou para o
âmbito individual os problemas da inserção social, do emprego e do desempenho profis-
sional e fez da educação um "valor econômico", numa equação perversa que equipara
capital e trabalho como se fossem ambos igualmente meros "fatores de produção" (das
teorias econômicas neoclássicas) (MINTO, 2020, s/p. - grifos do autor).

Um dos efeitos da política adotada pelo Banco Mundial é inserir nas funções públicas (universidade e escolas), valores e critérios do mercado (eficiência, eficácia, produtividade, competitividade, competências, entre outros), deixando como resíduo da solidariedade. Igualmente, a elaboração das políticas setoriais, como as políticas públicas para a educação, fica subordinada às políticas de ajuste estrutural, que entra em contradição com os objetivos declarados (CORÁGGIO apud SILVA JUNIOR, 2003).

Sguissardi (2006) destaca que frente às pressões e às recomendações desses órgãos, os governos latino-americanos sentiram-se impelidos a realizar mudanças que contribuíram para o redesenho das universidades. A direção tomada, neste período, foi o encaminhamento de instituições orientadas para o mercado e a competição através dos níveis de qualidade. Essas mudan-

4 Consultar mais informações em Frigotto (1995) e Rossi (1978). 
ças, fruto das crises da sociedade capitalista, impacta na vida material objetiva e subjetiva dos sujeitos, porque perpassa pela esfera da produção, do mercado, do Estado e no âmbito ideológico-político-cultural.

Contudo, é imprescindível e urgente pensar que tipo de educação e sociedade se quer. Um "cidadão-consumidor" em que a concorrência seja a única forma de vida ao invés da convivência, ou uma forma alternativa a esse domínio. "A educação não deve qualificar para o mercado, mas para a vida" (MÉSZÁROS, 2008, p. 10). Nesse sentido, romper com a educação como mercadoria, em respeito existência humana. Isto emerge como fundamental para pensar a sociedade tendo como parâmetro o ser humano que exige a superação da lógica desumanizadora do capital, tendo no individualismo, no lucro e na competição seus princípios básicos.

\section{Metodologia de pesquisa}

A investigação científica é um ato de construção, onde cada elemento envolvido não é apenas um dado e/ou informação, ao contrário, contribui de maneira singular para o desenvolvimento de respostas adequadas ao problema. O desenvolvimento satisfatório de uma investigação cientifica está intimamente ligado ao compromisso assumido pelo investigador em relação ao objeto pesquisado, por isso com base na abordagem qualitativa, este texto foi construído por meio da pesquisa bibliográfica e documental (PADUA, 1997).

Uma abordagem crítica requer destacar que: "A pesquisa educacional, tal como ela vem sendo realizada, compreende, assim, uma vasta diversidade de questões, de diferentes conotações, embora todas relacionadas complexamente ao desenvolvimento das pessoas e das sociedades" (GATTI, 2007, p. 13).

O corpus analítico teve como base o documento chave preliminar o Relatório Anual do Banco Mundial de 2017 e o Relatório sobre o Desenvolvimento Mundial de 2018, que enfatiza a proposta de 'Aprender para concretizar a promessa de educação'.

O referencial teórico-crítico foi constituído por Harvey (2004), Dardot e Laval (2016) para entender o modo de produção capitalista, a lógica neoliberal e o papel do Estado; Pereira (2018) que discute o papel do Banco Mundial e os ajustes fiscais na América Latina; Mészáros (2008) desvelando críticas à educação como um negócio e defendendo que é uma alavanca essencial de mudança/transformação e emancipação humana; Mancebo (2010) que tece reflexões sobre a privatização e a mercantilização do conhecimento, entre outros para um posicionamento crítico a respeito da temática elencada nesta investigação.

\section{AS INFERÊNCIAS E ANÁlises: RELATório ANUAL Do BM (2017) E RELATÓRIO DE DESENVOLVIMENTO MUNDIAL (2018)}

O Relatório Anual do Banco Mundial de 2017 foi organizado pelas Diretorias Executivas do Banco Internacional de Reconstrução e Desenvolvimento (BIRD) e Associação Internacional de Desenvolvimento (AID) que são conhecidos como agentes que compõem o Banco Mundial. Neste documento, há duas metas a serem alcançadas: a) erradicar a pobreza extrema até 2030 mediante a redução da percentagem de pessoas que vivem com menos de US\$1,90 por dia e; b) impulsionar a prosperidade compartilhada mediante a promoção do aumento da renda dos $40 \%$ mais pobres em cada país. Para atingi-las, propôs a parceria entre os setores sociais (público e privado). 
Em 2016, o banco apoiou países em desenvolvimento com um total de US\$ 61,8 bilhões em empréstimos, subsídios, investimentos de capital e garantias a países parceiros e empresas privadas. Verificar contemplados com investimento/empréstimos no quadro:

Quadro 1 - Apoio financeiro do BM

\begin{tabular}{|l|l|}
\hline \multicolumn{1}{|c|}{ PAÍSES } & \multicolumn{1}{|c|}{ VALOR CONCEDIDO } \\
\hline América Latina e Caribe & US\$ 9,7 bilhões \\
\hline Europa e Ásia Central & US\$ 9,5 bilhões \\
\hline Leste Asiático e Pacífico & US\$ 9,7 bilhões \\
\hline Sul da Ásia & US\$ 9,6 bilhões \\
\hline Oriente Médio e Norte da África & US\$ 7,1 bilhões \\
\hline África Subsaariana & US\$ 16,2 bilhões \\
\hline
\end{tabular}

Fonte: Adaptado de Banco Mundial (2017 e 2019).

Nos últimos anos, as parcerias público-privadas, estão cada vez mais presentes na área educacional por meio de políticas públicas educacionais, por isso importa refletir dentre aquelas metas proposta pelo BM a que diz respeito ao investimento nas pessoas para construir capital humano. No relatório anual (2017), é considerado como aptidões coletivas e capacidade de uma população, sendo "um fator determinante crítico do crescimento econômico e da redução da pobreza" (p. 24).

Na parte do relatório anual/2017 que trata do investimento nas pessoas para a construção do capital humano há sete temas que merecem ser analisados. Neles é possível uma análise dialética do papel do BM, desvelando seu papel mobilizador, que não é aparente, no fortalecimento e expansão e valorização do capital.

No primeiro item, financiamento com base em resultados: enfoque bem-sucedido do documento destaca-se:

O enfoque do Banco Mundial no investimento em capital humano visa a promover o acesso universal a serviços sociais de alta qualidade por meio de sistemas responsáveis para educação, saúde e proteção social que possam produzir resultados, especialmente para as pessoas mais pobres do mundo (BANCO MUNDIAL, 2017, p. 26 - grifo nosso).

É perceptível que o desenvolvimento humano é medido pela lógica de mercado, ou seja, pela produção de resultados, isto é, pela racionalidade neoliberal. Outro ponto questionável é, diante aos ajustes fiscais, no caso brasileiro, como estão sendo realmente prestados os serviços essenciais do Estado como educação, saúde e proteção social, será que com alta qualidade conforme sinaliza o documento.

$\mathrm{O}$ item segundo apoiar crianças, meninas adolescentes e mulheres ressalta que as "experiências na primeira infância têm um profundo impacto no desenvolvimento do cérebro, afetando a aprendizagem, saúde, produtividade na vida adulta e, em última instância, a competitividade econômica dos países" (BANCO MUNDIAL, 2017, p. 26). Nesse sentido, merecem investimentos e cuidados. A pergunta que deve ser feita é se as iniciativas a serem tomadas concebem uma educação para a vida-trabalho ou apenas para beneficiar o mercado.

No terceiro tópico, facilitação do empoderamento econômico das mulheres - aponta que o "objetivo é aumentar a capacidade da mulher de se expressar e de defender seus direitos em casa, na comunidade e em diversos níveis do governo, bem como levar homens e rapazes a desenvol- 
ver soluções de igualdade de gênero" (BANCO MUNDIAL, 2017, p. 26). Nesse descrito, o conceito de empreendedorismo é ressaltado como uma forma de emprego e inserção no mercado de trabalho. Contudo, essa disposição de se projetar e realizar serviços e negócios em muitos casos abrange um mercado informal, sem direitos sociais.

No quarto, promoção da proteção social universal, o BM visa a promover o desenvolvimento inclusivo ajudando os países a construir sistemas de identificação seguros e eficientes. Já o item seguinte considera a ajuda na realização da cobertura universal da saúde que representa o "apoio que presta aos clientes enfoca três áreas principais: assegurar a prestação eficaz de serviços de saúde; promover a proteção contra risco financeiro; e mobilizar os esforços de outros setores para melhorar os resultados da saúde e nutrição" (BANCO MUNDIAL, 2917, p. 28).

$\mathrm{O}$ item sexto abordagem da desigualdade de renda por meio de serviços financeiros abrange a discussão sobre inclusão financeira, sendo que uma forma de abordar a desigualdade da renda e proporcionar a oportunidade econômica é trazer indivíduos sem conta bancária ao sistema financeiro, que é formal e regulado. "O acesso a esses serviços permite às pessoas abrir e expandir empresas, investir na educação, gerenciar o risco e suportar choques financeiros" (BANCO MUNDIAL, 2017, p. 28).

No último item, garantia da urbanização sustentável,

Um bilhão de pessoas vivem hoje em favelas e, embora 80\% do PIB seja gerado em áreas urbanas, a exclusão social, a desigualdade e a pobreza crescem rapidamente nas cidades. Por meio de seu trabalho em desenvolvimento urbano, o Banco Mundial visa a construir cidades e comunidades sustentáveis, utilizando um processo de urbanização inclusivo, resiliente, produtivo e habitável (BANCO MUNDIAL, 2017, p. 28).

O Relatório Anual/2017 apresenta aspectos consideráveis em relação aos itens acima que abordam temas relevantes e que merecem atenção do Estado. De acordo com o relatório, para os dezessete países da região da América Latina e Caribe, que dispõem de microdados, a parcela da população que vive com US\$3,20 por dia ou menos, o limiar da pobreza extrema na região, decresceu de 24,7\% em 2003 para 11,6\% em 2013. No total, 63,3 milhões de pessoas saíram da pobreza.

Porém, durante os dois últimos anos a redução da pobreza permaneceu inalterada, dois quintos da população permanecem vulneráveis a cair na pobreza e o ritmo de crescimento diminuiu. É inegável os elementos de caráter prático nas ações do Banco Mundial, contudo, é questionável seu papel não aparente, juntamente com os outros organismos multilaterais como instrumentos na defesa dos interesses americanos. Ao resgatar a história Pereira (2018) aponta a situação da América Latina nos anos 1980.

No caso da América Latina, a pressão liberalizante dos EUA aumentaria após a crise da dívida externa em 1982, cuja gestão se converteu em mecanismo para disciplinar as políticas econômicas dos países devedores, conforme o credo neoliberal emergente. Entre 1980-1985, os programas de ajuste impulsionaram a liberalização do comércio, o alinhamento dos preços ao mercado internacional, a desvalorização da moeda, o fomento à atração de investimento externo, a especialização produtiva e a expansão das exportações primárias. Ao mesmo tempo, no âmbito das políticas sociais e da administração estatal, o ajuste prescrevia como meta a redução do déficit público mediante o corte de gastos com pessoal e custeio da máquina administrativa, a redução drástica de subsídios ao consumo popular, a redução do custo per capita dos programas, a reorientação da política social para saúde primária e educação básica como mínimos sociais e 
a focalização do gasto em grupos em extrema pobreza. O modus operandi, batizado de "tratamento de choque", tinha de ser rápido e intenso para mostrar comprometimento à banca internacional e evitar a articulação da oposição interna (p. 2191 - grifos do autor).

Nesse sentido, a investida das políticas de ajuste fiscal e revisão do papel do Estado, bem como de suas instituições para a construção de economias de mercado. Essa racionalidade adentra na educação com as reformas educacionais com propositivas de investir em capital humano (Educação Básica e saúde primária).

No atual contexto, as reformas neoliberais não querem a minimização do Estado, mas uma reconfiguração profunda de sua ação em favor de novos interesses e objetivos, isto é, dos interesses financeiros mais globalizados, privatização e desnacionalização das economias e expropriação de direitos sociais e trabalhistas em favor do capital (PEREIRA, 2018).

Com relação ao Relatório de Desenvolvimento Mundial (RDM) de 2018, sua análise recai no aprender para concretizar a promessa de educação, isto é, realça a necessidade de equidade nos resultados da aprendizagem, que as escolas e o sistema trabalhem tendo em vista a aprendizagem dos alunos (BANCO MUNDIAL, 2018).

A preocupação apontada neste relatório ${ }^{5}$ está nos resultados insatisfatórios de milhões de jovens estudantes de países de renda baixa e média que enfrentam empregos com salários mais baixos. Isso acontece, segundo as estatísticas fora da idade-série/ano porque a Educação Básica não educou para serem bem-sucedidos na vida, além é claro de outras dificuldades durante a vida escolar.

Diante desse contexto, questiona-se que sem a aprendizagem a educação não cumprirá sua promessa de eliminar a pobreza extrema e criar oportunidade e prosperidade compartilhadas para todos em busca da equidade social. Segundo o BM, mesmo após vários anos de escolarização, milhões de crianças mal sabem ler, escrever ou matemática básica. Essa crise de aprendizagem está ampliando as lacunas sociais em vez de estreitá-las. Jovens estudantes, já em posição de desvantagem devido à pobreza, conflito, gênero ou deficiência, chegam à idade adulta sem as aptidões básicas para a vida. Deste modo,

Esta crise de aprendizagem é uma crise moral e econômica. [...] quando bem ministrada à educação promete aos jovens emprego, melhores rendas, boa saúde e vida sem pobreza. Para as comunidades a educação promove a inovação, fortalece as instituições e incentiva a coesão social. Mas esses benefícios dependem da aprendizagem e a escolarização sem aprendizagem é uma oportunidade perdida. Mais do que isso, é uma grande injustiça: as crianças a quem a sociedade não atende são as que mais necessitam de uma boa educação para serem bem-sucedidas na vida (BANCO MUNDIAL, 2017).

Medidas políticas concretas para ajudar os países em desenvolvimento solucionarem essa crise são sugeridas, por meio de avaliações mais sólidas de aprendizagem e mobilização de um forte movimento social, para impulsionar mudanças na educação cujo lema seja aprender para todos, conceitos similares já utilizados na década de noventa por Delors (1988).

Embora nem todos os países em desenvolvimento sofram de tais lacunas extremas na aprendizagem, muitos estão muito aquém dos níveis a que aspiram. As principais avaliações de alfabetização e aritmética mostram que nos países pobres o estudante médio tem um desempenho abaixo de $95 \%$ dos estudantes nos países de alta renda - significando que nesses países tal estudante seria alvo de atenção corretiva em sala de aula. Muitos

5 Advertência à respeito da "crise da aprendizagem" na educação global (BANCO MUNDIAL. 2019). 
estudantes de alto desempenho nos países de renda média - jovens, tanto homens como mulheres que se enquadram no quartil superior de seus grupos - se classificariam no quartil inferior em um país mais rico (BANCO MUNDIAL, 2017).

O relatório oferece três recomendações políticas, que são fundamentadas na assessoria obtida durante as consultas aos vinte países, governos, organizações de desenvolvimento e pesquisas, organizações da sociedade civil e setor privado. $\mathrm{O}$ quadro que segue apresenta detalhamento:

Quadro 2 - Recomendações políticas

\begin{tabular}{|l|l|l|}
\hline $\begin{array}{l}\text { RECOMENDAÇÕES } \\
\text { POLÍTICAS }\end{array}$ & $\begin{array}{l}\text { 1. Avaliar a aprendizagem para que } \\
\text { se torne uma meta verificável }\end{array}$ & $\begin{array}{l}\text { 1.1 Proporcionar avaliações estruturadas } \\
\text { para que os professores possam orientar os } \\
\text { alunos, melhorar a gestão e chamar a aten- } \\
\text { ção da sociedade na aprendizagem. }\end{array}$ \\
\cline { 2 - 4 } & $\begin{array}{l}\text { 2. Fazer as escolas trabalharem } \\
\text { para todas as crianças } \\
\text { gem e promover o desenvolvimento, atrair } \\
\text { ao magistério pessoas qualificadas e moti- } \\
\text { vá-las com treinamentos, utilizar tecnolo- } \\
\text { gias que ajudem os professores e reforçar a } \\
\text { direção à escola, incluindo os diretores. }\end{array}$ \\
\cline { 2 - 5 } & $\begin{array}{l}\text { 3.1 Mobilizar cidadãos, aumentar a respon- } \\
\text { sabilidade e criar a vontade política de uma } \\
\text { reforma da educação. } \\
\text { ressadas na aprendizagem }\end{array}$ \\
& $\begin{array}{l}\text { 3.2 Envolver pessoas interessadas, inclusi- } \\
\text { ve a comunidade empresarial, em todas as } \\
\text { etapas da reforma da educação, do desenho } \\
\text { à implementação. }\end{array}$ \\
\hline
\end{tabular}

Fonte: Banco Mundial (2017).

As preocupações apresentadas no RDM (2018) são inquietações de qualquer Estado em desenvolvimento, dos governos, escolas, universidades e profissionais da educação. De fato, a Educação Básica e Superior, tem esse potencial de desenvolvimento e crescimento humano, cultural, intelectual e profissional. Contudo, com uma leitura mais crítica percebe-se a lógica mercadológica e privatista implícita na proposta para sanar os resultados insatisfatórios de aprendizagem. Como melhorar a aprendizagem se muitos governos aderem políticas e ajuste fiscal, para que haja resultados satisfatórios é necessário investimento nas escolas, nas universidades públicas e condições de trabalho aos profissionais.

Ao discutir sobre a privatização e mercadorização da Educação Superior, Mancebo (2010, p. 9) alerta que a preocupação com a lógica privatizante deve ir além, pois está relacionada com "o enxugamento do financiamento público para a educação" ou "a abertura do campo para a iniciativa de empresas comerciais de ensino". É fundamental se preocupar com "a privatização de forma indireta, mas nem por isso menos eficaz: aquela que pode ocorrer pela introdução de mecanismos de administração e gerenciamento empresariais nas instituições públicas educacionais, especialmente para a busca de recursos no mercado".

No caso brasileiro, vive-se o enxugamento do Estado, do financiamento público para Educação Básica e Superior, resultando na total desvalorização dos profissionais da área, que coloca em risco a qualidade da aprendizagem e do ensino. Corrobora-se o que enfatizam Pereira e Silva (2018), as "instituições e intelectuais do campo privado-mercantil operam um processo de 
privatização na e da Educação, alterando seu caráter público e estatal, transformando-a em um nicho de investimentos financeiros" (p. 523). Por fim, é possível inferir que a correlação de forças entre capital e trabalho, por meio da resistência organizada dos movimentos sociais é o princípio basilar para a defesa do direito à educação pública.

\section{Considerações Finais}

As análises preliminares dos documentos sinalizam que essa instituição financeira propõe uma agenda em que aposta no papel ativo do Estado na construção de economias de mercado, competitivas e globalizadas. O Banco Mundial é chamado para assumir um papel nítido no sentido de organizar a economia. Assim, sua ação vai se configurando mais politizada, abrangente e intrusiva. Há muito que se pesquisar e analisar sobre as práticas do Banco Mundial e sua incidência na reestruturação das políticas sociais brasileiras.

A manutenção dos países na condição de dependência financeira diante um contexto de ajuste fiscal e a objetivação da lógica de mercado (menor custo/mais produtividade) nas políticas públicas educacionais, se faz presente na formação (básica e superior).

Os dois relatórios supracitados ao longo desta análise (Relatório Anual do Banco Mundial de 2017 e o Relatório sobre o Desenvolvimento Mundial de 2018) abordam questões sociais e educacionais consideráveis e que afetam o desenvolvimento dos países em todas as esferas da sociedade. Contudo, apostar apenas na área da educação como responsável ou promessa de eliminar a pobreza extrema, criando oportunidade e prosperidade compartilhadas para todos, seria utopia, sobretudo, num contexto de ajustes fiscais, privatização e precarização da ciência, principalmente no contexto brasileiro vivenciado nesse último ano.

Isto revela a necessidade urgente, de reiterar a defesa da educação pública e gratuita, e de excelência, enquanto direito de todos, assegurada pelo Estado-democrático, como forma de combater as desigualdades. As parcerias público-privado são portas de entrada para a privatização e mercantilização da educação. Frente a esse cenário, é imprescindível reafirmar que não se quer o fim da gratuidade da Educação Básica e Superior, conforme recomenda o Banco Mundial, que beneficia uma parcela da população, a mais rica enquanto os mais pobres ficam à deriva do processo.

Para mudar essa realidade, vale-se do investimento público para subsidiar as escolas e universidades, a formação dos professores, estrutura física e material, valorização e condições de trabalho dignas a todos os profissionais da educação. Isto demanda o fortalecimento do Estado e, uma concepção que "não deve qualificar para o mercado, mas para a vida" (MÉSZÁROS, 2008, p. 10). Educação não é uma mercadoria, deve-se respeitar a existência humana. Para isso, emerge a necessidade de pensar a sociedade tendo como parâmetro o ser humano, exige-se fundamentalmente, a superação da lógica desumanizadora do capital, que tem no individualismo, no lucro e na competição seus princípios basilares.

\section{WORLD BANK (BM) RECOMMENDATIONS FOR BRAZILIAN EDUCATIONAL PUBLIC POLICIES}

ABSTRACT: Historically, higher education reforms in Latin America have been influenced by the World Bank, which follows hegemonic thinking, in addition to the diagnosis made by international organizations. Education is considered by these agencies as the driving force behind economic development and the fight against inequality. 
However, betting on education alone will not solve the social problem. This text aims to understand the current proposals of the World Bank that are present in the construction of public educational policies in developing countries like Brazil. Based on the qualitative approach, this text was constructed through bibliographic and documentary research. Preliminary analyzes of the documents signal that the BM is called upon to take a clear role in organizing the economy. Its action is becoming politicized, comprehensive and intrusive. There is much to be researched and analyzed about their practices and the impact on the restructuring of Brazilian social policies.

KEYWORDS: Public Policies. International Organizations. State.

\section{REFERENCIAS}

BANCO MUNDIAL. Relatório anual do Banco Mundial 2017. Disponível em: https://www. worldbank.org/. Acesso em: 11 fev. 2019.

BANCO MUNDIAL. Relatório sobre o desenvolvimento mundial 2018. Disponível em: https://www. worldbank.org/. Acesso em: 30 jul. 2019.

BANCO MUNDIAL. O Banco Mundial adverte a respeito da "crise da aprendizagem" na educação global. Comunicado à imprensa. 2017. Disponível em: https://www.worldbank.org/pt/news/pressrelease/2017/09/26/world-bank-warns-of-learning-crisis-in-global-education. Acesso em: 14 fev. 2019.

CHESNAIS, François. Mundialização: o capital financeiro no comando. Les Temps Modernes, 607, 2000.

DARDOT, Pierre; LAVAL, Christian. A nova razão do mundo: ensaio sobre a sociedade neoliberal. Tradução Mariana Echalar. São Paulo: Boitempo, 2016.

DELORS, Jacques. et all. Educação um tesouro a descobrir. Relatório para a UNESCO da Comissão Internacional sobre Educação para o século XXI. UNESCO. 1998.

FRIGOTTO, Gaudêncio. Educação e a crise do capitalismo real. São Paulo: Cortez, 1995.

GATTI, Bernadete Angelina. A construção da pesquisa em educação no Brasil. Brasília: Liber, 2007.

HARVEY, David. Condição pós-moderna. São Paulo: Loyola, 1994.

HARVEY, David. O novo imperialismo. São Paulo: Loyola, 2003.

HARVEY, David. Espaços de esperança. São Paulo: Loyola, 2004.

MANCEBO, Deise. Reforma universitária: reflexões sobre a privatização e a mercantilização do conhecimento. Educação e Sociedade. Campinas, v. 25, n.88, p. 845-867, 2010.

MÉSZÁROS, István. A crise estrutural do capital. São Paulo: Boitempo, 2011

MÉSZÁROS, István. A educação para além do capital. São Paulo: Boitempo, 2008.

MINTO, Lalo. Teoria do capital humano. Disponível em: http://www.histedbr.fe.unicamp.br/ navegando/glossario/verb c teoria \%20do capital humano.htm. Acesso em: 13 maio 2020.

OLIVEIRA, Dalila Andrade. Política educacional e a re-estruturação do trabalho docente: reflexões sobre o contexto latino-americano. Educação e sociedade. Campinas, v. 28, n. 99, p. 355-375, maio/ago. 2007. Disponível em: http://www.cedes.unicamp.br. Acesso em: 13 nov. 2018.

PADUA, Elisabete Matallo Marchesini. Metodologia da pesquisa: abordagem teórico-prática. 5. ed. Campinas: Papirus, 1997.

PEREIRA, João Márcio Mendes. Banco Mundial, reforma dos Estados e ajuste das políticas sociais na América Latina. Ciência \& saúde coletiva. 23(7), p. 2187-2196, 2018.

PEREIRA, Rodrigo da Silva; SILVA, Maria Abádia. Estado capitalista brasileiro e organismos internacionais: continuidades e aprofundamentos das reformas educacionais. HISTEDBR On-line. Campinas, v.18, n.2(76), p. 523-544, abr./jun. 2018.

PERONI, Vera Maria Vidal. Mudanças na configuração do estado e sua influência na política educacional. IN: PERONI, Vera Maria Vidal; BAZZO, Vera Lúcia; PEGORARO, Ludimar. (Org.) Dilemas da educação brasileira em tempos de globalização neoliberal: entre o público e o privado. Porto Alegre: UFRGS, 2006.

ROSSI, Wagner. Capitalismo e educação: contribuição ao estudo crítico da economia da educação capitalista. São Paulo: Cortez e Moraes, 1978. 
SILVA JUNIOR, João dos Reis. Reformas do estado e da educação e as políticas públicas para a formação de professores a distância: implicações políticas e teóricas. Revista brasileira de educação. set/out/nov/ dez, n. 24, 2003.

SOUZA, Aparecida Neri de. Trabalhar na universidade pública no Brasil, lugar de trabalho, qual trabalho? ABET, v. 17, n. 1, jan. jun. 2018. 